\title{
Comment
}

\section{Reflexões sobre os Saberes da Ação para a Formação Docente}

\author{
José de Caldas Simões Neto ${ }^{1}$; Lireida Maria Albuquerque Bezerra ${ }^{2}$
}

\begin{abstract}
Resumo: Os problemas sociais atuais e o descaso do poder público com grande parte da sociedade nos levam a pensar na escola e na educação como um lugar de resistência, onde o conhecimento e saber estão veiculados nas capacidades dos estudantes para contestar toda e qualquer forma de exclusão. O docente precisa saber relacionar a base teórica ao seu dia a dia para ensinar bem e alcançar bons resultados. A partir dessa afirmativa o presente texto tem como foco principal refletir sobre os saberes da ação necessários para uma prática efetiva no ambiente educacional. Essa teórica pedagógica dos saberes da ação pedagógica tem como relação de complementação estabelecida entre os saberes disciplinares, os saberes curriculares, os saberes das ciências da educação, os saberes da tradição pedagógica e os saberes experienciais. Ninguém nasce um cidadão, a ideia de participação social precisa ser permanentemente construída. Esse trabalho educacional deve ser norteado nos saberes e conteúdos atitudinais, com ações no cotidiano, no fazer no processo de aprendizagem. As escolas e universidades têm que inserir atividades pedagógicas que levem a reflexão, ao entendimento crítico dos eventos da sociedade onde estão inseridas, deve estar preocupado com a vida de todos, com o meio ambiente e com as questões sociais.
\end{abstract}

Palavras-chave: Educação. Formação. Docentes.

\section{Reflections on Knowledge action for Teacher Training}

\begin{abstract}
The current social problems and the neglect of the government with much of society, lead us to think in school and education as a place of resistance, where knowledge and know are served in the capabilities of students to challenge all forms of exclusion. Teachers need to know to relate the theoretical basis to their daily lives to teach well and achieve good results. From this statement in this study as a main objective to reflect on the action of knowledge necessary for effective practice in the educational environment. This pedagogical theoretical knowledge of pedagogical action is to complement the relationship established between disciplinary knowledge, curricular knowledge, the knowledge of the sciences of education, knowledge of the pedagogical tradition and experiential knowledge. No one is born a citizen, the idea of social participation must be permanently built. This educational work should be guided in knowledge and atitudianis content with actions in daily life, in making the learning process. Schools and universities have to insert educational activities that lead to reflection, critical understanding of society events where it operates, be concerned with the lives of all, the environment and social issues.
\end{abstract}

Keywords: Education. Formation. Teachers.

\section{Introdução}

Um dos maiores desafios da educação é oferecer ferramentas para estudo, análise e compreensão da sociedade contemporânea, onde as inúmeras situações de exclusão de direitos e de condições dignas de sobrevivências inviabilizam uma grande parcela de sujeitos em praticarem a sua cidadania.

\footnotetext{
${ }^{1}$ Docente do Curso de Licenciatura em Educação Física no Centro Universitário Dr. Leão Sampaio - Mestrando em Educação pela Anne Sullivan University - Juazeiro do Norte - Ceará - Brasil. E-mail: josecaldas@ leaosampaio.edu.br

${ }^{2}$ Geógrafa pela Faculdade de Filosofia do Crato. Especialização em Ciências na área de Concentração Geo ambiente. Mestre em Geografia pela Universidade Federal do Ceará. Professora da Universidade Regional do Cariri. E-mail: lireida.mabe@gmail.com.
} 
Ao longo da nossa história lutamos para a garantia do acesso a saúde, a educação, a segurança e a outros direitos, que como cidadãos temos. Essa situação de exclusão esta desestimulando a proposta política dos projetos neoliberais com as promessas de estabilidade monetária, política e de um governo democrática. Gentile (1996, p. 14) discorre que:

[...] é simplesmente, um sistema político que deve permitir aos indivíduos desenvolver a sua inegável capacidade de livre escolha na única esfera que garante e potencializa a referida capacidade individual: o mercado. De certa forma a crise é produto da difusão excessiva aos olhos de certos neoliberais atentos da noção de cidadania. Para eles, o conceito de cidadania em que se baseia a concepção universal e universalizante dos direitos humanos (políticos, sociais, econômicos, culturais etc.) tem gerado um conjunto de falsas promessas que orientam ações coletivas individuais caracterizadas pela improdutividade e pela falta de reconhecimento social no valor individual da competição.

As mídias atualmente são os meios de difusão destes discursos neoliberais, como a incorporação dos novos conceitos de terceirização, globalização, modernização e privatização para a população, dão as mídias um "poder" de supremacia para um ideal de uma sociedade com concepção coletiva e solidária.

Para Azevedo (1997, p. 13) "No que diz respeito às políticas sociais, a referência básica é igualmente o livre mercado". Porém as políticas neoliberais implementadas na educação pública se torna contraditória e desagregadora, pois ao mesmo tempo em que prega uma descentralização das ações, elas transfere responsabilidades de órgãos centrais e concentra na tomada de decisões e fiscalização, distanciado o poder público das suas responsabilidades sociais. As escolas assim são organizadas de tal forma a difundir uma concepção de mundo, de sociedade e de homem através de sua ação educativa.

Nesse contexto vamos refletir sobre a formação crítica dos docentes e sobre os saberes da ação necessários para uma prática efetiva no ambiente educacional para a formação de cidadãos e profissionais atuantes na sociedade.

\section{Reflexões Sobre os Saberes}

A educação hoje deve contribuir para desvendar e compreender essas relações, como também perceber o modo como a sociedade onde vivemos se organiza. Além disso, precisamos 
Id on Line Revista Multidisciplinar e de Psicoloqia

Id on Line Multidisciplinary Journal and Psycology

nos comprometer com aqueles que ainda vêm sendo excluídos, principalmente do acesso ao saber. A prática educativa da escola deve estar pautada nesse sentindo, onde a escola é um espaço de inclusão e comprometida com a socialização e democratização dos conhecimentos.

Os problemas sociais atualmente e o descaso do poder público com grande parte da sociedade, nos levam a pensar na escola e na educação como um lugar de resistência, onde o conhecimento e o saber estão veiculados nas capacidades dos estudantes para contestar toda e qualquer forma de exclusão.

Nesse espaço, o educador segundo Xavier (1994) deve compreender o processo através da realidade da sociedade e histórica brasileira, que foi e vem sendo produzida, para que assim possa identificar os pontos determinantes, para transformar esses pontos em ferramentas eficazes de interpretação e reflexão sobre os problemas educacionais e sociais brasileiros. Desta maneira professores e estudantes, irão perceber esse espaço que ocupam como seres históricos e inseridos numa prática pedagógica que pode transformar a sua realidade.

Os docentes precisam saber relacionar a base teórica ao seu dia a dia para ensinar bem e alcançar bons resultados. Torna-se fundamental discutir essas questões no âmbito educacional, pelo fato de além de estarem formando novos profissionais, mas, sobretudo segundo Freire (1996) que nenhuma transformação político-social do mundo se concretiza se não parte de uma compreensão de homem e de mulher enquanto seus fazedores da história e por ela feitos, seres de decisão, de ruptura, de opção, seres éticos.

Por muito tempo, sendo mais específico no século $\mathrm{XX}$, os professores formados nas escolas normais, tinham uma prática e métodos de ensino para ensinar as crianças a ler e escrever através apenas, com base nos saberes da ação, que eram adquiridos nos estágios em escolas de aplicação anexas às escolas normais e pelas interações com seus pares, metodologias muito eficazes até hoje. Não tinham conhecimentos teóricos da linguística, nem das áreas da psicologia e sociedade ou mesmo da didática. Que atualmente, esses conhecimentos são indispensáveis. Pois, através desses saberes os profissionais adquirem capacidade e habilidades de análise crítica que permitem discutir a sua própria ação (CHARTIER, 2010).

A autora fala ainda dos saberes da ação e dos saberes científicos, onde exemplifica que para se formar e poder exercer bem a sua profissão, um médico precisa dominar os saberes científicos, obtidos no curso universitário, e os saberes da ação, aprendidos durante o trabalho em hospitais, onde ele compartilha com outros médicos, enfermeiros e outros profissionais da 
Id on Line Revista Multidisciplinar e de Psicoloqia

Id on Line Multidisciplinary Journal and Psycology

área, o atendimento a pacientes. Se ele tiver somente o saber científico, pode até se tornar um bom conhecedor da medicina, mas jamais será um bom médico. Com os professores, ocorre situação semelhante. Ou seja, sem a prática, o educador não será eficiente em sala de aula (CHARTIER, 2010).

Para Tardif (2002) apud Cardoso; Pino e Dorneles (2012, p. 2) destacam a existência de quatro tipos diferentes de saberes implicados na atividade docente, a saber:

A) Saberes da Formação Profissional - Conjunto de saberes que, baseados nas ciências e na erudição, são transmitidos aos professores durante o processo de formação inicial e/ou continuada. Também se constituem o conjunto dos saberes da formação profissional os conhecimentos pedagógicos relacionados às técnicas e métodos de ensino (saber-fazer), legitimados cientificamente e igualmente transmitidos aos professores ao longo do seu processo de formação.

B) Saberes Disciplinares - São os saberes reconhecidos e identificados como pertencentes aos diferentes campos do conhecimento (linguagem, ciências exatas, ciências humanas, ciências biológicas, etc.). Esses saberes, produzidos e acumulados pela sociedade ao longo da história da humanidade, são administrados pela comunidade científica e o acesso a eles deve ser possibilitado por meio das instituições educacionais.

C) Saberes Curriculares - São conhecimentos relacionados à forma como as instituições educacionais fazem a gestão dos conhecimentos socialmente produzidos e que devem ser transmitidos aos estudantes (saberes disciplinares). Apresentam-se, concretamente, sob a forma de programas escolares (objetivos, conteúdos, métodos) que os professores devem aprender e aplicar.

D) Saberes Experienciais - São os saberes que resultam do próprio exercício da atividade profissional dos professores. Esses saberes são produzidos pelos docentes por meio da vivência de situações específicas relacionadas ao espaço da escola e às relações estabelecidas com alunos e colegas de profissão.

Nesse sentido, "incorporam-se à experiência individual e coletiva sob a forma de hábitos e de habilidades, de saber-fazer e de saber ser” (TARDIF, 2002, p. 38). O autor chama a atenção para os saberes experienciais, que se justifica pela relação de exterioridade. É no exercício e no cotidiano de sua atuação profissional, que poderá vivenciar situações concretas. A partir das quais, se faz necessário desenvolver habilidades, capacidades de interpretação, tomada de decisão e improvisação, assim como segurança poderá ter experiência e escolher as melhores estratégias diante do problema apresentado na sua prática.

Para Gauthier et al. (2006), os saberes experienciais partem do momento em que se tornam públicos e são validados em pesquisas realizadas tendo como cenário empírico a sala 
Id on Line Revista Multidisciplinar e de Psicoloqia

Id on Line Multidisciplinary Journal and Psycology

de aula. Essa ideia do autor diz respeito à necessidade de se avaliar e validade os saberes experienciais, no sentido de que possa possibilitar a construção de uma teoria pedagógica.

Essa teórica pedagógica dos saberes da ação pedagógica tem como relação de complementação estabelecida entre os saberes disciplinares (sobre a matéria a ser ensinada), os saberes curriculares (sobre o programa de ensino), os saberes das ciências da educação (resultado do processo de formação inicial dos professores), os saberes da tradição pedagógica (elementos do ser professor provenientes de uma representação específica de escola e de atividade docente, relacionada com sua vivência de aluno) e os saberes experienciais (resultado das experiências do cotidiano e da interpretação subjetiva de sua validade). Esses saberes para os autores que direcionam o docente para a tomada de decisão na escola, de melhores estratégias e metodologias para sua atuação profissional, no caso dos professores na sala de aula.

\section{Considerações Finais}

No processo de formação e história da educação em nosso país, passou e passa por grandes transformações e influenciada pelos fatores econômicos, políticos e sociais de cada período. Para o filosofo Norbert Elias onde o homem e a sociedade estão diretamente ligados, dessa forma se a sociedade muda o homem muda, se o homem muda a sociedade também muda.

Com esse pensar filosófico, que podemos refletir e buscar a transformação da nossa sociedade através de ações que transformem os sujeitos, para assim podermos tentar modificar as questões e problemas de exclusão de nossa sociedade. Essa transformação deve iniciar pela educação, na formação de profissionais capazes de refletir na ética e na moral de cada profissão.

A partir de uma sociedade repleta de sujeitos que exerça sua cidadania de maneira efetiva, respeitando o meio ambiente nas questões de sustentabilidade, na atuação profissional com amor e respeito para as pessoas, seguir os caminhos que são jurados para sua profissão em sua formatura, onde se jura a dedicação à vida profissional a serviço da humanidade, respeitando a dignidade e os direitos humanos, a cumprir com ética e honestidade sua função perante a sociedade.

Muitos desses discursos não esquecidos após esse momento de solenidade de formatura, profissionais que "cruza os braços" e "fecham os olhos" para situações de exclusão. Nosso país, nos estado, nossa cidade, nossa comunidade, nossa escola, nossa casa precisa de cidadão, 
críticos, ativos, reflexivos e atuantes, a fim de cumpri com os deveres e garantir os diretos de todos. Os saberes científicos são essenciais para a formação profissional, porém o saber da ação é a "chave" certa para a porta da garantia dos direitos de cada um.

Ninguém nasce um cidadão, a ideia de participação social precisa ser permanentemente construída. Esse trabalho educacional deve ser norteado nos saberes e conteúdos atitudinais, com ações no cotidiano, no fazer no processo de aprendizagem. As escolas e universidades têm que inserir atividades pedagógicas que levem a reflexão, ao entendimento crítico dos eventos da sociedade onde esta inserida, estar preocuparam com a vida de todos, com o meio ambiente e com as questões sociais.

Ações sociais levam ao desenvolvimento das capacidades e argumentação com base na realidade vivida, permitindo diferentes percursos e estratégias para incentivar a reflexão e novas possibilidades das relações humanas, ligadas a compreensão de como o poder é exercício e como se delineiam as responsabilidades nas inter-relações sociais, cabendo aos educadores e orientadores educacionais possibilitar ações e um meio que permita ser sempre de caráter formativo.

\section{Referências}

AZEVEDO, J M. L. de. A Educação como política pública. Campinas: Autores Associados, 1997.

FREIRE, P. Pedagogia da autonomia. São Paulo: Paz e Terra,1996.

XAVIER, M. E.; et al. História da educação: A escola no Brasil. São Paulo: FTD, 1994.

GENTILI, P. (org). Pedagogia da exclusão. Crítica ao neoliberalismo em educação. Rio de Janeiro: Ed. Vozes, 1995.

TARDIF, Maurice. Saberes docentes e formação profissional. $4^{a}$ Ed. Rio de Janeiro: Vozes, 2002.

CHARTIER, A-M. Alfabetização. Ensinar a ler e escrever, entre teoria e prática. In: Conferência Proferida na Fundação Victor Civita (FVC), São Paulo. 2010. 
CARDOSO, A. A. et al. Os saberes profissionais dos professores na perspectiva de Tardif e Gauthier: contribuições para o campo de pesquisa sobre os saberes docentes no Brasil. IX ANPED SUL. Seminário de Pesquisa em Educação da Região Sul, Caxias do Sul, 2012.

GAUTHIER, Clermont et al. Por uma teoria da pedagogia: pesquisas contemporâneas sobre o saber docente. $2^{\text {a }}$ ed. Ijuí: Editora Unijuí, 2006.

Como citar este artigo (Formato ABNT):

SIMÕES NETO, J. de C.; BEZERRA, L.M.A. Reflexões sobre os saberes da ação para a formação docente. Id on Line Revista Multidisciplinar e de Psicologia, Set-Out/2016, vol.10, n.31, p. 241-247. ISSN 1981-1179.

Recebido: 17/08/2016.

Aceito: 20/08/2016 